\title{
Anatomia foliar de Copaifera langsdorffii Desf. (Leguminosae): interpretações ecológicas em diferentes condições edáficas de Cerrado
}

\author{
João Carlos Ferreira de Melo Júnior ${ }^{1 *}$ \\ Cleusa Bona ${ }^{2}$ \\ Gregório Ceccantini ${ }^{3}$ \\ ${ }^{1}$ Laboratório de Anatomia Vegetal, Departamento de Ciências Biológicas \\ Universidade da Região de Joinville, Rua Paulo Maschitzki, 10, CEP 89219-710, Joinville - SC, Brasil \\ ${ }^{2}$ Laboratório de Anatomia Vegetal, Departamento de Botânica \\ Setor de Ciências Biológicas, Universidade Federal do Paraná, Curitiba - PR, Brasil \\ ${ }^{3}$ Laboratório de Anatomia Vegetal, Departamento de Botânica \\ Instituto de Biociências, Universidade de São Paulo, São Paulo - SP, Brasil \\ * Autor para correspondência \\ joao.melo@univille.br
}

Submetido em 05/03/2012

Aceito para publicação em 16/08/2012

\section{Resumo}

Copaifera langsdorffi Desf. (Caesalpinioideae, Leguminosae) é uma espécie arbórea de ampla distribuição no Brasil, conhecida como copaíba. O presente trabalho objetiva discutir, numa perspectiva ecológica, alterações estruturais foliares em populações de copaíba em três substratos distintos no Cerrado: neossolo flúvico em margem de rio, afloramento arenítico e latossolo vermelho em campo cerrado. Atributos foliares qualitativos e quantitativos foram observados por meio de preparações histológicas permanentes. Diferenças estatisticamente significativas foram verificadas em todos os parâmetros ecológicos analisados, como área específica foliar, espessura de tecidos e densidade estomática. A presença mais acentuada de características escleromórficas foi constatada nas plantas de arenito e neossolo flúvico, embora o latossolo também seja pobre em bases trocáveis. As alterações estruturais encontradas sejam o resultado da combinação de fatores edáficos, hídricos, microclimáticos e da interação planta/herbívoros existente em cada substrato, porém percebe-se claramente que houve prevalência dos fatores nutricionais do solo em detrimento da disponibilidade de água.

Palavras-chave: Cerrado; Copaifera; Esclerofilia; Morfologia funcional

\section{Abstract}

Leaf anatomy of Copaifera langsdorffii Desf. (Leguminosae): ecological interpretations based on different soil conditions in the Cerrado. Copaifera langsdorffii Desf. (Caesalpinioideae, Leguminosae) is a tree known as copaiba that is widely distributed in Brazil. The present paper discusses, from an ecological perspective, leaf structural changes in populations of copaiba found growing in three different substrates in the Cerrado: alluvial neosoil on riverbanks, sandstone and red latosol in savanna. Qualitative and quantitative leaf traits were observed from permanent histological preparations. Statistically significant differences were observed in all of the ecological parameters analyzed, such as specific leaf area, tissue thickness and stomatal density. A 
higher proportion of scleromorphic features was found in plants growing on the sandstone and alluvial neosoil, although the latosol was also low in exchangeable bases. The structural changes observed were the result of the combination of soil factors, water, microclimate and plant/herbivore interaction related to each substrate; it was clear that soil nutrients had more influence on these changes than water availability.

Key words: Cerrado; Copaifera; Functional morphology; Sclerophylly

\section{Introdução}

A vegetação de Cerrado, responsável pela cobertura de $23 \%$ do território brasileiro e com limite austral em áreas disjuntas no estado do Paraná (LOPES; COX, 1977; EITEN, 1994), tem sofrido transformações crescentes em função da atividade agropecuária. Visando a criação de estratégias voltadas à conservação e manejo deste bioma tornam-se necessários os trabalhos que contribuam com o entendimento da sua diversidade vegetal em termos estruturais e funcionais (FREITAS; OLIVEIRA, 2002).

Apesar da diversidade vegetal ser interpretada, freqüentemente, por informações resultantes de levantamentos florísticos e fitossociológicos (NUNESFREITAS, 2004), diversos autores tem apontado que dados morfológicos e anatômicos também podem mostrar os padrões de diversidade existentes num dado ecossistema e o seu potencial adaptativo (ex. RURY, 1985; BARROS et al., 2006).

Dentre as espécies arbóreas consideradas representativas no Cerrado, Copaifera langsdorffii Desf., conhecida em geral como copaíba ou pau-d'óleo, destaca-se por ser encontrada em distintas fisionomias como áreas de cerrado stricto sensu, cerradão, matas ciliares e áreas florestais ectonais (SARMIENTO, 1983; FELFILI; SILVA-JÚNIOR, 1992).

Sugere-se que a ampla distribuição geográfica de $C$. langsdorffii em áreas de Cerrado seja reflexo do potencial plástico exibido pela espécie em resposta aos diferentes regimes ambientais aos quais está submetida, produzindo diferenças morfológicas e anatômicas intraespecíficas em suas populações. Registros feitos por Dwyer (1951), Lewis (1987) e Gentry (1996) de espécimes com 13m de altura em áreas florestais e $2 \mathrm{~m}$ em indivíduos em campo cerrado tornam a copaífera uma planta chave para compreender a influência das condições ambientais sobre seu potencial adaptativo.
Este trabalho tem como objetivo diagnosticar diferenças estruturais foliares quali-quantitativas de populações de $C$. langsdorffii associadas ao potencial adaptativo em diferentes condições edáficas de uma área de Cerrado meridional.

\section{Material e Métodos}

O trabalho foi realizado em área planáltica de Cerrado pertencente ao Parque Estadual do Cerrado ( $24^{\circ} 09^{\prime} \mathrm{S}$ e $\left.50^{\circ} 18^{\prime} \mathrm{W}\right)$, localizado no município de Jaguariaíva, PR, com área de 420,2ha (Figura 1). Situado a uma altitude de 750-900m, apresenta clima temperado $(\mathrm{Cfb})$, segundo classificação de Köppen, com temperatura média de $22^{\circ} \mathrm{C}$ nos meses mais quentes. A precipitação pluviométrica é de $1300 \mathrm{~mm} /$ ano, havendo registro de mais de cinco geadas noturnas anuais (MAACK, 1968; IAP, 1999). A área é composta por diferentes tipos de solos (EMBRAPA, 1984; UHLMANN et al., 1998), sendo que a espécie em estudo encontra-se em substratos dos tipos: latossolo em campo cerrado, afloramentos areníticos e neossolo flúvico em margem de rio.

Em cada substrato foram selecionados 10 espécimes de $C$. langsdorffii, totalizando um grupo amostral de 30 plantas, nas quais foram coletadas 30 folhas de sol completamente expandidas do 3 ํ e $4^{\circ}$ nós, a partir do ápice de cada ramo. Destas, 20 foram usadas para mensuração do peso fresco $(\mathrm{g})$, sendo em seguida prensadas e secas em estufa para determinação do peso seco $(\mathrm{g})$, área foliar $\left(\mathrm{cm}^{2}\right)$ através de imagem digitalizada em scanner de mesa acoplado Sigma Scan Pro (version 4.0, SPSS Inc., Chicago IL, USA) e área específica foliar (AEF, $\mathrm{cm}^{2} / \mathrm{g}^{-1}$ ) (WITKOWSKI; LAMONT, 1991). Em virtude da folha de $C$. langsdorffii ser composta, foi utilizado o folíolo basal em todas as análises. 
FIGURA 1: Localização da área de estudo e pontos de coleta.

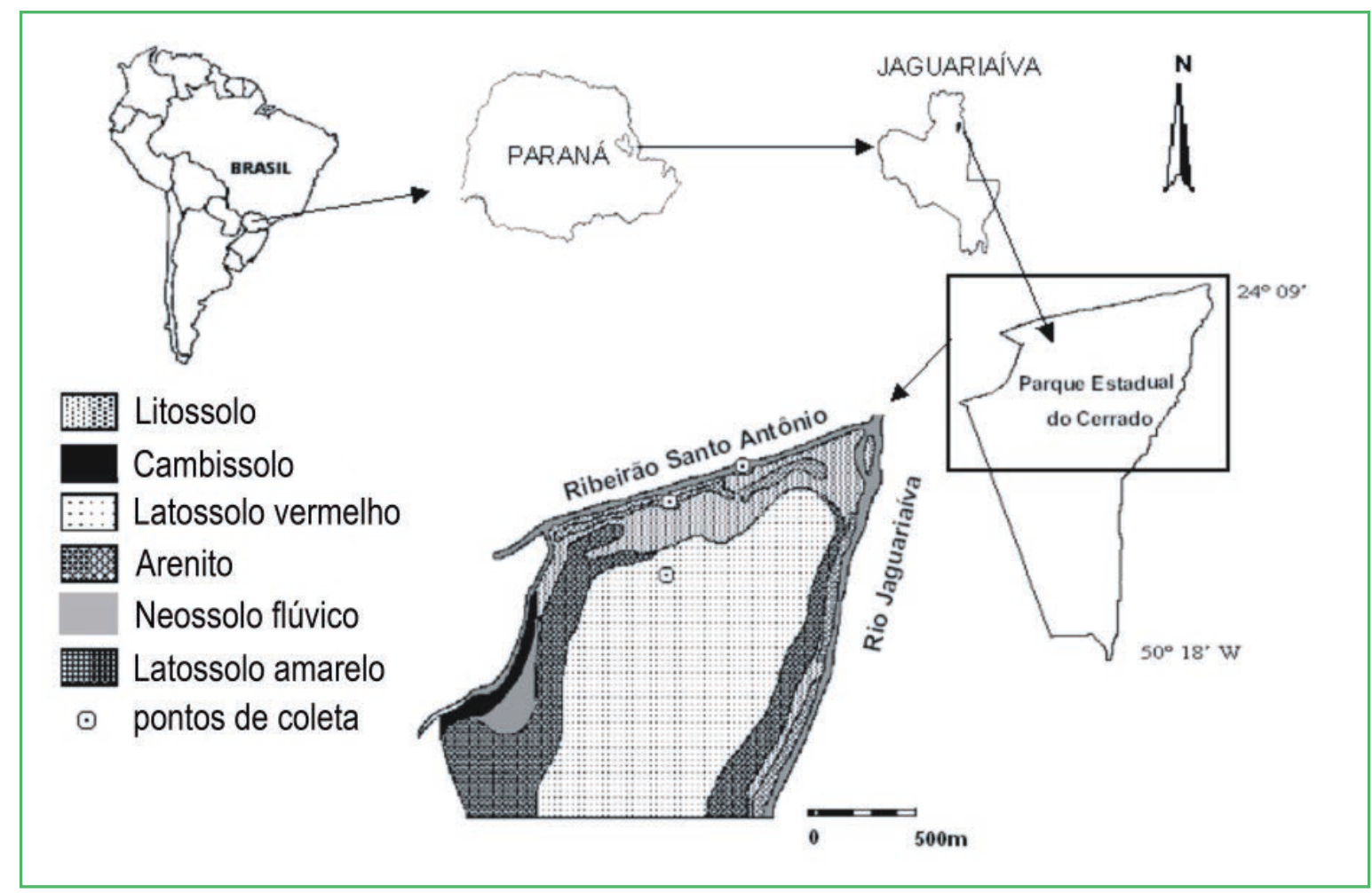

As demais folhas foram fixadas em campo em FAA 50 para análise anatômica (JOHANSEN, 1940). Preparações histológicas permanentes do terço médio da lâmina foram obtidas por emblocamento em historresina (GMA-glicol metacrilato) (FEDER; O’BRIEN, 1968), sendo os blocos seccionados em micrótomo rotatório com cerca de $5 \mu \mathrm{m}$ de espessura. Os cortes histológicos foram corados com azul de toluidina (O'BRIEN et al., 1965) e montados com resina sintética.

A densidade estomática foi feita com projeção de imagem em câmara clara empregando-se objetiva de $10 \mathrm{x} / 1 \mathrm{~mm}^{2}$ de superfície foliar a partir de preparações histológicas paradérmicas obtidas pela técnica da modelagem em esmalte incolor (BOEGER; GLUZEZAK, 2006). Os tecidos foliares foram mensurados em microscópio fotônico com ocular micrometrada.

Para a comparação entre as médias dos valores de cada variável analisada aplicou-se ANOVA e teste de Tukey com $\mathrm{p}=0,05$.

\section{Resultados e Discussão}

A área foliar apresentou diferença significativa entre as populações de C. langsdorffi, sendo os folíolos de maior área, com valor médio de 3,6 e $3,5 \mathrm{~cm}^{2}$, encontrados em plantas de latossolo e arenito, respectivamente, diferindo das plantas de neossolo flúvico com média de $2,8 \mathrm{~cm}^{2}$ (Tabela 1 ). Inversamente ao esperado para as plantas com maior aporte hídrico, como demonstrado por Faleiro e Saiki (2007) em dez espécies de mata de galeria em área de Cerrado, folíolos com menores áreas em margem de rio podem ser entendidos como uma resposta da planta ao grau de exposição à radiação solar uma vez que ocupa o dossel da mata ciliar. Os indivíduos em margem de rio estavam mais expostos em decorrência do seu porte, com altura média de $6 \mathrm{~m}$, enquanto que os indivíduos de latossolo, com altura média de $2 \mathrm{~m}$, estavam ligeiramente sombreados por outras espécies e os de arenito exibiam formas reptantes. 
TABELA 1: Parâmetros morfo-anatômicos das folhas de Copaifera langsdorffii em relação aos substratos estudados no Parque Estadual do Cerrado.

\begin{tabular}{|c|c|c|c|}
\hline Parâmetros $\quad$ Substratos & Latossolo & Arenito & Neossolo flúvico \\
\hline $\operatorname{Peso} \operatorname{seco}(g)$ & $0,010-\mathbf{0 , 0 3 8}-0,098(0,017) \mathrm{A}$ & $0,017-\mathbf{0 , 0 4 4}-0,103(0,017) \mathrm{B}$ & $0,011-\mathbf{0 , 0 3 2}-0,072(0,012) \mathrm{C}$ \\
\hline Área foliar $\left(\mathrm{cm}^{2}\right)$ & $1-\mathbf{3 , 6}-8,5(1,4) \mathrm{A}$ & $1,3-\mathbf{3 , 5}-8,2(1,2) \mathrm{A}$ & $1,2-\mathbf{2 , 8}-5,4(0,9) \mathrm{B}$ \\
\hline Densidade estomática $\left(\mathrm{n}^{0} / \mathrm{mm}^{2}\right)$ & $48-\mathbf{6 0}-71(6,4) \mathrm{A}$ & $58-72-96(9,6) \mathrm{B}$ & $63-\mathbf{8 1}-103(12,6) \mathrm{C}$ \\
\hline Área específica foliar $\left(\mathrm{cm}^{2} / \mathrm{g}^{-1}\right)$ & $72,5-96,2-130,2(10) A$ & $68,7-\mathbf{8 3 , 3}-108,8(7,5) \mathrm{B}$ & $71,5-\mathbf{8 9 , 2}-143(9,8) \mathrm{C}$ \\
\hline Espessura total do limbo (mm) & $155-179-206(17,1) A$ & $184-214-265(20,3) B$ & $190-\mathbf{2 0 5}-226(10,4) \mathrm{C}$ \\
\hline Epiderme da face adaxial (mm) & $15-\mathbf{1 7}-21(1,7) \mathrm{A}$ & $17-\mathbf{2 0}-27(2,8) \mathrm{B}$ & $17-\mathbf{1 9}-23(1,9) \mathrm{C}$ \\
\hline Parênquima paliçádico (mm) & $58-74-86(7,4) \mathrm{A}$ & $96-\mathbf{1 2 2}-148(16,7) \mathrm{B}$ & $96-\mathbf{1 1 4}-123(8,6) \mathrm{C}$ \\
\hline Parênquima lacunoso (mm) & $59-74-92(10,9) \mathrm{A}$ & $44-\mathbf{5 5}-73(9,6) \mathrm{B}$ & $44-\mathbf{5 8}-79(11,2) \mathrm{C}$ \\
\hline Epiderme da face abaxial (mm) & $10-\mathbf{1 4}-17(1,7) \mathrm{A}$ & $13-\mathbf{1 6}-19(1,9) \mathrm{B}$ & $13-\mathbf{1 5}-17(1,6) \mathrm{C}$ \\
\hline
\end{tabular}

Valor mínimo - média - valor máximo (desvio-padrão). As letras diferentes indicam significância p $<0,05$.

Em plantas mais diretamente expostas ao sol é esperada a redução da área foliar (DICKISON, 2000; LARCHER, 2000). De acordo com Brünig (1973), a redução da área foliar pode ser uma estratégia de conservação de água em plantas que se desenvolvem em solos com menor capacidade de reter água e com baixa fertilidade.

A redução do tamanho da lâmina foliar também pode contribuir para elevar sua estabilidade mecânica (ROTH-NEBELSICK et al., 2001). Niklas (1996) verificou em Acer saccharum Marsh. (Aceraceae) que o desenvolvimento de estratégias biomecânicas, tal qual a produção de folhas pequenas, ocorre em indivíduos mais expostos ao vento. Entretanto, Pianka (1978) ressalta que o tamanho das folhas resulta da interação de outros fatores, além da predominância dos ventos, como a intensidade luminosa incidente (CUTTER, 2002), a disponibilidade hídrica em níveis mais elevados da copa (EVERT, 2006) e a herbivoria (EDWARDS; WRATTEN, 1981).

A condição hipoestomática, com células estomáticas localizadas ao nível das demais células epidérmicas, foi uma constante entre os indivíduos estudados. $\mathrm{O}$ confinamento dos estômatos na superfície abaxial do limbo é o padrão de distribuição mais comum em plantas terrestres (SMITH; MCCLEAN, 1989), sendo considerado resultante da adaptação à economia de água devido à maior exposição da face adaxial à luz solar (LLERAS, 1977). Trabalhos clássicos para a flora do Cerrado evidenciam esta tendência (MORRETES; FERRI, 1959; MORRETES, 1967; 1969).

Os valores médios da densidade estomática em cada ambiente foram inversamente proporcionais à área foliar, decrescendo significativamente do neossolo flúvico para o latossolo (Tabela 1). Estudos com Tapirira guianensis Aubl. (BOEGER et al., 1998) apontam que a densidade estomática tende a ser inversamente proporcional à diminuição da área foliar, enquanto Larcher (2000) afirma que folhas mais sombreadas tendem a compensar a baixa freqüência de estômatos aumentando sua área foliar. Espécies de Cerrado em geral devem apresentar maior densidade estomática, sendo esta uma adaptação relacionada a ambientes onde a disponibilidade de água é determinante (Pearce et al., 2006). Salisbury (1927) e Lleras (1977) concluíram que as plantas xeromórficas apresentam maior densidade estomática por unidade de área. Desta forma é permitida uma troca de gases mais eficiente nos períodos em que a umidade relativa é alta e quando o período de desidratação excessiva é mínimo.

Situação similar foi demonstrada por Rossatto et al. (2009), em diferentes espécies de cerrado, as quais apresentaram menor área foliar e maior densidade estomática nas folhas mais expostas da copa, características que indicam condições mais secas 
(MEDRI; LLERAS, 1979). Uma vez que o neossolo flúvico é constantemente lixiviado e pobre em bases trocáveis, Loveless (1962) acrescenta que o aumento na freqüência de estômatos é também uma característica associada à deficiência de nitrogênio.

Os dados de AEF sugerem que as plantas de arenito e neossolo flúvico são mais esclerófilas em relação às de latossolo (Tabela 1). Possivelmente isso se deva a uma maior disponibilidade de nutrientes no latossolo, quando comparado aos demais substratos. $\mathrm{O}$ latossolo, mesmo considerado um solo pobre em bases trocáveis, ainda oferece às comunidades nele instaladas aporte nutricional superior aos demais substratos aqui considerados.

Dentre os significados funcionais atribuídos à esclerofilia, acredita-se que, neste estudo, esta característica seja uma conseqüência a solos com baixa concentração de nitrogênio e fósforo e alto teor de cálcio, fator que aumenta a produção de estruturas esclerificadas (LOVELESS, 1962; BEADLE, 1966; TURNER, 1994a; MEZIANI; SHIPLEY, 1999); ou uma intensificação da longevidade da folha devido à maior proteção, reduzindo a herbívoria (TURNER, 1994b; GRUBB, 1986), uma vez que foi constatado em campo que os indivíduos de $C$. langsdorffii não exibiam lesões foliares provocadas pelo ataque de herbívoros. Para os indivíduos encontrados sobre o arenito pode ainda refletir uma adaptação ao déficit de água (OERTLI et al., 1990).

De acordo com Edwards e Sanso (2000), a esclerofilia também pode ser definida em termos de propriedade mecânica, apesar de pouco estudada em função das dificuldades metodológicas. Além de funcionar como agentes de reforço mecânico que reduzem os efeitos provocados pela dessecação (ROTHNEBELSICK et al., 2001), o esclerênquima pode estar relacionado com a demanda de água na planta à medida que folhas esclerófilas tendem a reconstituir lesões no xilema mais rapidamente que folhas não esclerófilas (ARENS, 1958; AOKI; SANTOS, 1979; SALLEO et al., 1997).

A anatomia foliar apresentou a mesma tendência encontrada para os parâmetros morfológicos de forma com que os indivíduos de latossolo diferissem estatisticamente dos indivíduos de arenito e neossolo flúvico, que por sua vez mostraram maior similaridade estrutural. Folhas mais delgadas ocorreram em plantas de latossolo, com espessura média de $179,5 \mu \mathrm{m}$, enquanto as mais espessadas decorrentes do incremento em volume das células do mesofilo foram observadas nas plantas de arenito e neossolo flúvico. Parênquima paliçádico mais desenvolvido foi constatado nos indivíduos de arenito e neossolo flúvico em relação aos de latossolo, ao passo que o parênquima lacunoso mostrou proporção inversa (Tabela 1).

Os dados encontrados indicam que as variações estruturais no mesofilo dos indivíduos de C. langsdorffi foram provocadas pelas distintas condições de exposição à luminosidade às quais estavam submetidos. Resultados similares foram verificados por Voltan et al. (1992) em trabalho com cultivares de Coffea arabica L. (Rubiaceae) expostos a diferentes intensidades luminosas, indicando que em condições de radiação elevada ocorre espessamento foliar induzido pela expansão volumétrica das células do mesofilo e pelo alongamento celular do parênquima paliçádico. Em alguns casos tal fator pode ser acompanhado pelo acréscimo de camadas celulares e redução dos espaços intercelulares (MEDRI; LLERAS, 1979; THOMPSON et al., 1992; VOLGEMANN, 1994; MARQUES et al., 2000), sendo reconhecido por Evert (2006) como uma característica tipicamente xeromórfica.

Evert (2006) e Cutter (2002) sugerem que o aumento na intensidade luminosa, além de proporcionar o aumento na espessura das folhas, promove um incremento na massa foliar específica, no desenvolvimento da epiderme e do parênquima e no número total de células da folha. Esta tendência, observada nas populações de C. langsdorffii estudadas, também foi verificada em Sebastiania myrtilloides (Mart.) Pax. (Marques et al., 1999) e em Lavoisiera bergii Cogn., Macairea radula (Bonpl.) DC. e Trembleya parviflora (D. Don) Cogn. (Somavilla e Graciano-Ribeiro, 2011), em trabalhos realizados em áreas de Cerrado.

Variação na espessura da epiderme, incluindo a cutícula, também foi reconhecida como caráter distintivo entre os ambientes, sendo tal tecido mais espesso nos indivíduos de arenito e neossolo flúvico quando comparados aos de latossolo (Tabela 1). 
Este resultado é similar ao de Marques et al. (2000), que observaram em duas espécies de Miconia, ocorrentes em Cerrado, que as folhas mais expostas ao sol apresentam um incremento em espessura da cutícula e da epiderme da face adaxial. Relacionadas à perda de água pela planta em ambientes xéricos, estruturas como cutícula espessa e tricomas desempenham função similar, podendo também estar ligadas ao isolamento térmico do mesofilo exposto ao calor excessivo (ROTH, 1984; EVERT, 2006). Por ser uma estrutura compacta e composta por células de parede espessa, a epiderme também apresenta importância mecânica, especialmente quando possui reforço cuticular (PYYKKÖ, 1979).

Epidermes mais desenvolvidas na superfície foliar adaxial, além de reduzir o déficit de água provocado pelo processo de transpiração em folhas mais expostas diretamente à irradiância solar e temperaturas altas (METCALFE; CHALK, 1979; CUTTER, 2002; EVERT, 2006), auxiliam na secagem da folha devido ao rápido escoamento da água (SMITH; MCCLEAN, 1989); protege a planta contra ataques de herbívoros (COLEY, 1983); e aumenta a reflexão da luz incidente (CHADZON; KAUFMANN, 1993).

Em suma, os resultados obtidos neste estudo corroboram a ideia apontada por Edwards e Wratten (1981), de que, devido às pressões ambientais, as plantas podem desenvolver ao longo do tempo estruturas físicas diferenciadas.

Considerando a similaridade entre os pontos de coleta no que tange às condições de temperatura, umidade do ar e regime pluviométrico, pode-se inferir a hipótese de que as alterações estruturais encontradas seja o resultado da combinação de fatores edáficos, hídricos, microclimáticos e da interação planta/ herbívoros existente em cada substrato. Porém, percebese claramente que houve prevalência dos fatores nutricionais do solo em detrimento da disponibilidade de água, a qual parece assumir um caráter secundário.

Muito embora o latossolo apresente baixos teores de bases trocáveis (EMBRAPA, 1999), a presença mais acentuada de características escleromórficas foi constatada nas plantas de arenito e neossolo flúvico, sinalizando que o maior déficit nutricional nestes substratos decorra do pouco ou quase ausente acúmulo de serrapilheira e do alto grau de lixiviação dos nutrientes. Boeger et al. (2004) sugere que tais características são estratégias desenvolvidas pelas plantas para sobreviver em condições adversas em solos oligotróficos.

A formação de condições microclimáticas mais amenas, que favoreçam a redução de caracteres xeromorfos nos indivíduos de Copaifera do latossolo, pode estar relacionada à co-habitação de outras espécies arbóreas de igual ou maior porte contrapondo a situação de isolamento dos indivíduos amostrados nos outros ambientes estudados. A organização fisionômica das diferentes espécies ocorrentes no latossolo possibilitaria maior proteção aos ventos incidentes sobre a copa, formação de uma micro-atmosfera mais úmida e redução da quantidade de energia radiante sobre as folhas devido à formação mútua de barreiras constituídas pelas copas mais desenvolvidas, além da suavização dos efeitos danosos provocados por herbívoros.

\section{Referências}

AOKI, H.; SANTOS, J. R. Fatores ambientais dos cerrados e imagens orbitais. Boletim Técnico do Instituto Florestal, v. 31, p. 1-69, 1979.

ARENS, K. O cerrado como vegetação oligotrófica. Boletim de Botânica da USP, São Paulo, v. 15, p. 59-77, 1958.

BARROS, C. F.; MARCON-FERREIRA, M. L.; CALLADO, C. H.; LIMA, H. R. P.; CUNHA, M.; MARQUETE, O.; COSTA, C. G. Tendências ecológicas na anatomia da madeira de espécies da comunidade arbórea da Reserva Biológica de Poço das Antas, Rio de Janeiro, Brasil. Rodriguésia, Rio de Janeiro, v. 57, n. 3, p. $443-$ 460, 2006.

BEADLE, N. C. W. Soil phosphate andits role in molding segments of the Australian flora vegetation, with special reference to xeromorphy and scleromorphylly. Ecology, New York, v. 47, p. 992-1007, 1966.

BOEGER, M. R. T.; ALVES, L. C.; NEGRELLE, R. R. B. Variações morfo-anatômicas dos folíolos de Tapirira guianensis Aubl. em relação a diferentes estratos da floresta. Biotemas, Florianópolis, v. 11, n. 2, p. 27-38, 1998.

BOEGER, M. R. T.; ALVES, L. C.; NEGRELLE, R. R. B. Leaf morphology of 89 tree species from a lowland tropical rain forest (Atlantic Forest) in south Brazil. Brazilian Archives of Biology and Technology, Curitiba, v. 47, n. 6, p. 933-943, 2004.

BOEGER, M. R. T.; GLUZEZAK, R. M. Adaptações estruturais de sete espécies de plantas para as condições ambientais da área de dunas de Santa Catarina, Brasil. Iheringia, Porto Alegre, v. 61, n. 1-2, p. 73-82, 2006. 
BRÜNIG, E. F. Species rickness and stand diversity in relation to site and succession forests in Sarawak and Brunei (Borneo). Amazoniana, Manaus, v. 4, p. 293-320, 1973.

CHAZDON, R. L.; KAUFMANN, S. Plasticity of leaf anatomy of two rain forest shurbs in relation to photosynthetic light acclimation. Functional Ecology, London, v. 7, p. 385-394, 1993.

COLEY, P. D. Herbivory and defensive characteristics of tree species in a lowland tropical forest. Ecological Monographs, New York, v. 53, n. 2, p. 209-23, 1983.

CUTTER, E. G. Anatomia vegetal: órgãos. 2 ed. São Paulo: Roca, 2002. 304 p.

DICKISON, W. C. Integrative plant anatomy. San Diego: Harcourt/ Academic Press, 2000. 533 p.

DWYER, J. D. The central american, west indian and south american species of Copaiferai (Caesalpinaceae). Brittonia, New York, v. 7, n. 3, p. 143-172, 1951.

EDWARDS, C. R. J.; SANSO, G. Characterising sclerophylly: some mechanical properties of leaves from heath and forest. Oecology, Heidelberg, v. 123, p. 158-167, 2000.

EDWARDS, P. J.; WRATTEN, S. D. Ecologia das interações entre insetos e plantas. São Paulo: Edusp, 1981. 71 p.

EITEN, G. Vegetação. In: PINTO, M. N. (Ed.) Cerrado: caracterização, ocupação e perspectivas. Brasília: Editora da Universidade de Brasília, 1994. p. 17-73.

EMBRAPA - EMPRESA BRASILEIRA DE PESQUISA AGROPECUÁRIA. SERVIÇO NACIONAL DE LEVANTAMENTO E CONSERVAÇÃO DE SOLOS. Levantamento de reconhecimento de solos do Estado do Paraná. Londrina: IAPAR, 1984. 412 p.

EVERT, R. F. Esau's plant anatomy: meristems, cells and tissues of the plant body: their structure, function and development. 3 ed. New Jersey: Wiley, 2006. 601 p.

FALEIRO, W.; SAIKI, P. T. O. Morfologia Foliar em Cinco Fitofisionomias de Cerrado do Parque Estadual da Serra de Caldas Novas, GO. Revista Brasileira de Biociências, Porto Alegre, v. 5, supl. 1, p. 687-689, 2007.

FEDER, N.; O'BRIEN, T. P. Plant microtechnique: some principles and new methods. American Journal of Botany, Saint Louis, v. 55, n. 1, p. 123-142, 1968.

FELFILI, J. M.; SILVA JÚNIOR, M. C. Floristic composition, phytosociology and comparison of cerrado and gallery forests at Fazenda Água Limpa, Federal District, Brazil. In: FURLEY, P. A.; PROCTOR, J. A.; RATTER, J. A. (Ed.). Nature and dynamics of forest-savanna boudaries. London: Chapman \& Hall, 1992. p. 393-415.

FREITAS, C. V.; OLIVEIRA, P. E. Biologia reprodutiva de Copaifera langsdorffii Desf. (Leguminosae, Caesalpinioideae). Revista Brasileira de Botânica, São Paulo, v. 25, n. 3, p. 311-321, 2002.

GENTRY, A. H. A field guide to the families and genera of wood plants of northwest South America (Colombia, Ecuador, Peru). Chicago: University of Chicago Press, 1996. 918 p.

GRUBB, P. J. Sclerophylls, pachyphylls and pycnophylls: the natureand significance of hard leaf surface. In: JUNIPER B.; SOUTHWOOD R. (Ed.). Insects and the plant surface. London: Edward Arnold, 1986. p. 137-150.
IAP. Unidades de conservação do Estado do Paraná. Curitiba: DIBAP, 1999. $87 \mathrm{p}$.

JOHANSEN, D. A. Plant microtechnique. New York: McGrawHill, 1940. 523 p.

LARCHER, W. Ecofisiologia vegetal. São Carlos: RiMa, 2000. $439 \mathrm{p}$.

LEWIS, G. P. Legumes of Bahia. Kew: Royal Botanical Gardens, 1987. $369 \mathrm{p}$.

LLERAS, E. Differnces in stomatal number per unit area within the same species under different micro-environmental conditions: a working hypothesis. Acta Amazonica, Manaus, v. 7, n. 4, p. 473476, 1977.

LOPES, A. S.; COX, F. R. Cerrado vegetation in Brazil: an edaphic gradient. Agronomy Journal, Madison, v. 69, p. 828-831, 1977.

LOVELESS, A. R. Further evidences to support a nutricional interpretation of sclerophylls. Annals of Botany, Exeter, v. 26, p. 168-561, 1962.

MAACK, R. Geografia física do Estado do Paraná. Rio de Janeiro: José Olympio, 1968. 450 p.

MARQUES, A. R.; GARCIA, Q. S.; FERNADES, G. W. Effects of Sun and shade on leaf structure and sclerophylly of Sebastiania myrtilloides (Euphorbiaceae) from Serra do Cipó, Minas Gerais, Brazil. Boletim de Botânica da Universidade de São Paulo, São Paulo, v. 18, p. 21-27, 1999.

MARQUES, A. R.; GARCIA, Q. S.; REZENDE, J. L. P.; FERNANDES, G. M. Variations in leaf characteristics of two species of Micona in the Brazilian cerrado under different light intensities. Tropical Ecology, Varanasi, v. 41, n. 1, p. 47-60, 2000. MEDRI, M. E.; LLERAS, E. Anatomia foliar e ecologia de Bertolletia excelsa Humb. A. Benpl. (castanha-do-paráLecythidaceae). Acta Amazônica, Manaus, v. 9, n. 1, p. 15-25, 1979.

METCALFE, C. R.; CHALK, L. Anatomy of the dicotyledons. Oxford: Claredon Press, 1979. 1500 p.

MEZIANI, D.; SHIPLEY, B. Interacting determinants of specific leaf area in 22 herbaceous species: effects of irradiance and nutrient availability. Plant, Cell and Environment, Oxford, v. 22, p. 447459, 1999.

MOLANO-FLORES, B. Herbivory and calcium concentrations affect calcium oxalate crystal formations in leaves of Sida (Malvaceae). Annals of Botany, Madison, v. 88, p. 387-391, 2001. MORRETES, B. L. Contribuição ao estudo da anatomia das folhas de plantas do cerrado. II. Boletim da Faculdade de Filosofia Ciências e Letras da USP, São Paulo, v. 22, p. 209-244, 1967.

MORRETES, B. L. Contribuição ao estudo da anatomia das folhas de plantas do cerrado. III. Boletim da Faculdade de Filosofia Ciências e Letras da USP, São Paulo, v. 24, p. 209-244, 1969.

MORRETES, B. L.; FERRI, M. G. Contribuição ao estudo da anatomia das folhas de plantas do cerrado. Boletim da Faculdade de Filosofia Ciências e Letras da USP, São Paulo, v. 24, p. 7-70, 1959.

NIKLAS, K. J. Differences between Acer saccharum leavesfrom open and wind-protected sites. New Phytologist, Oak Ridge, v. 143, p. 19-31, 1996.

NUNES-FREITAS, A. F. Bromélias da Ilha Grande: variação inter-habitats na composição, riqueza e diversidade da comunidade. 
2004. 230 f. Tese (Doutorado em Botânica) - Universidade do Estado do Rio de Janeiro, Rio de Janeiro. 2004.

O'BRIAN, T. P.; FEDER, N.; MCCULLY, M. E. Polychromatic staining of plant cell walls by toluidine blue O. Protoplasma, Vienna, v. 59, p. 368-373, 1965.

OERTLI, J. J.; LIPS, S. H.; AGAMI, M. The strength of sclerophyllous cells to resist collapse due to negative turgor pressure. Acta Oecologica, Paris, v. 11, p. 281-289, 1990.

PEARCE, D. W.; MILLARD, S.; BRAY, D. F.; ROOD, S. B. Stomatal characteristics of riparian poplar species in a semi-arid environment. Tree Physiology, Washington, v. 26, p. 211-218, 2006.

PIANKA, E. R. Ecologia evolutiva. Barcelona: Omega, 1978. $365 \mathrm{p}$.

PYYKKÖ, M. Morphology and anatomy of leaves from some woody plants in a humid tropical forest of Venezuelan Guayana. Acta Botanica Fennica, Helsink, v. 12, p. 1-41, 1979.

ROSSATTO, D. R.; HOFFMANN, W. A.; FRANCO, A. C. Características estomáticas de pares congenéricos de cerrado e mata de galeria crescendo numa região transicional no Brasil Central. Acta Botanica Brasilica, Feira de Santana, v. 23, n. 2, p. 499-508, 2009.

ROTH, J. 1984. Stratification of tropical forests as seen in leaf structure. Hague: W. Junk, 1984. 521 p.

ROTH-NESELSICK, A.; UHL, D.; MOSBRUGGER, V.; KERP, $\mathrm{H}$. Evolution and function of leaf venation architecture: a review. Annals of Botany, Exeter, v. 87, p. 553-566, 2001.

RURY, P. M. Systematic and ecological wood anatomy of the Erythroxylaceae. IAWA Bulletin, Leiden, v. 6, n. 4, p. 365-397, 1985.

SALISBURY, E. J. On the causes and ecological significance of stomatal frequency, with special reference to woodland flora. Philosophical Transactions of Royal Society of London, London, v. 46, p. 1-65, 1927.

SALLEO, S.; NARDINI, A.; LO GULLO, M. A. Is sclerophylly of Mediterranean evergreens and adaptation to drought? New Phytologist, Oak Ridge, v. 135, p. 603-612, 1997.
SARMIENTO, G. The savanas of tropical America In: BOURLIERE, F. (Ed.). Ecosystems of the World. 13. Tropical Savanas. Amsterdam: Elsevier, 1983. p. 245-288.

SMITH, W. K.; MCCLEAN, T. M. Adaptative relationship between leaf water repellency, stomatal distribution and gas exchange. American Journal of Botany, Saint Louis, v. 76, n. 3, p. 465-469, 1989.

SOMAVILLA, N. S.; GRACIANO-RIBEIRO, D. Análise comparativa da anatomia foliar de Melastomataceae em ambiente de vereda e cerrado sensu stricto. Acta Botanica Brasilica, Feira de Santana, v. 25, n. 4, p. 764-775, 2011.

THOMPSON, W. A., KRIEDEMAN, P. E.; CRAIG, I. E. Photosynthetic response to light and nutrients in sun-tolerant and shade-tolerant rainforest trees. I growth, leaf anatomy and nutrient content. Australian Journal of Plant Physiology, Washington, v. 19, p. 1-18, 1992

TURNER, J. M. A quantitative analysis of leaf form in woody plants form the world's major broad-leaved forest types. Journal of Biogeography, Oxford, v. 24, p. 413-419, 1994a.

TURNER, J. M. Sclerophylly: primarily protective? Funcional Ecology, London, v. 8, p. 669-675, 1994b.

UHLMANN, A., GALVÃO, F.; SILVA, S. M. Análise da estrutura de duas unidades fitosisionômicas de savana (cerrado) no sul do Brasil. Acta Botanica Brasilica, Feira de Santana, v. 12, n. 3, p. 231-247, 1998.

VOGELMANN, T. Light within the plant. In: KENDRICH, R. E.; KROENBERG, G. H. M. (Ed.) Photomorphogenesis in plants. Dordrecht: Kluwer Academic Publishers, 1994. p. 491-535.

VOLTAN, R. B. Q.; FAHL, J. I.; CARELLI, M. L. C. Variação na anatomia foliar de cafeeiros submetidos a diferentes intensidades luminosas. Revista Brasileira de Fisiologia Vegetal, Brasília, v. 4, n. 2, p. 99-105, 1992.

WITKOWSKI, E. T. F.; LAMONT, B. B. Leaf specific mass confounds leaf density and thickness. Oecologia, Heidelber, v. 88, p. 486-493, 1991 